\title{
Feminismo, teoría y práctica de una arqueología científica
}

\author{
Feminism, theory and practice of a scientific archaeology
}

María Cruz Berrocal (*)

\begin{abstract}
RESUMEN
Este artículo revisa la arqueología feminista, fundamentalmente norteamericana, y su contribución a la comprensión de la arqueología como ciencia. Se sintetiza brevemente el origen y desarrollo de la arqueología feminista, su relación con la arqueología de género y la arqueología posprocesual, y su valor como crítica epistemológica de la disciplina. Se observa también el desarrollo de la arqueología feminista en España y su relación con la arqueología materialista histórica.
\end{abstract}

\begin{abstract}
The paper reviews American feminist archaeology and its emphasis on the scientific character of the discipline. It is a synthesis of the origin and development of feminist archaeology, its links to gender archaeology and postprocessual archaeology, and its value as an epistemological critique of the discipline. The paper also considers the development of feminist archaeology in Spain, and its link to historical materialist archaeology.
\end{abstract}

Palabras clave: Feminismo; Arqueología; Crítica; Epistemología; Punto de vista.

Key words: Feminism; Archaeology; Critique; Epistemology; Standpoint feminism.

\section{INTRODUCCIÓN}

La teoría feminista ha creado una práctica arqueológica de gran entidad a lo largo de las dos últimas décadas, especialmente en el ámbito anglosajón, escandinavo y también español. Las

(*) Grupo de Investigación Prehistoria Social y Económica. IH, CCHS, CSIC. c/Albasanz 26-28. Madrid 28037.

Correo electrónico: maria.berrocal@cchs.csic.es Recibido: 17-VI-2009; aceptado: 12-VIII-2009. aproximaciones teóricas son tan diversas que pueden enfrentarse, y desde luego no existen pautas o protocolos que establezcan cómo se debería hacer una arqueología feminista, porque no hay una manera. El feminismo es más bien una reflexión y distintas prácticas que resultan de dicha reflexión. Exige una toma de decisiones caso por caso. Y sobre todo, el feminismo es una práctica comprometida con la definición y los límites de lo que es la ciencia, su objetividad, y las implicaciones de adoptar un punto de partida teórico explícito.

Esta posición no es fácil, pero es precisamente ese carácter lo que da al feminismo su valor. Especialmente la tradición norteamericana es relevante en este contexto: hizo "oficial" al feminismo en arqueología, desplegó todo su potencial y puso de relieve sus problemas. Ha producido abundantes publicaciones de gran impacto, $\mathrm{y}$, sobre todo, es el feminismo más cientifista, por decirlo así. Sin contradicciones, el feminismo norteamericano ha estado siempre orientado a la construcción de una arqueología crítica.

La exposición formal de este aspecto concreto es el objeto principal de este artículo. La reivindicación del feminismo como estrategia política y como estrategia científica ha sido durante años un tema importante en la arqueología feminista norteamericana, pero el tema no está agotado: las cuestiones feministas se discuten solamente en entornos feministas y la marginalización de todos estos desarrollos teóricos es evidente. En parte, es posible achacarla a la popularización de la arqueología de género. El deslinde entre la arqueología feminista y la arqueología de género es un análisis completamente necesario en este contexto.

La arqueología feminista europea, quizá por una cuestión de tradición, parece haber estado 
desde el principio más ligada a cuestiones como los ciclos vitales, el cuerpo y la identidad (Conkey 2003: 869), en conexión con una tradición filosófica propiamente europea (fenomenalismo, estructuralismo). En España parece predominar el interés por el estudio de la reproducción y sus implicaciones sociales y de trabajo (por ejemplo, Picazo 1997; Sanahuja 1997a y 1997b, 2001, 2002; Castro et al. 1998; Colomer et al. 1999; González 2000; Balaguer y Oliart 2003; Castro et al. 2003; Sánchez Liranzo 2005b; Montón et al. 2008). La influencia que el marxismo ha ejercido en la arqueología feminista merece en mi opinión una atención especial.

Una última observación necesaria: no voy a utilizar la expresión "arqueólogos/as" (1) pero señalaré que, de 181 obras citadas en el texto, con 247 firmas, sólo 17 son de hombres -correspondientes a 16 autores- (no todas las referencias son de arqueología). Esta pequeña cuantificación cualifica bien el peso de las mujeres en la producción arqueológica feminista, incluso mejor que la expresión cerrada de "arqueólogos/as", que implica, a veces falsamente, que los hombres y las mujeres han trabajado igual en todos los ámbitos. Esta homogeneización de la realidad es poco informativa.

\section{ARQUEOLOGÍA DEL GÉNERO VS. ARQUEOLOGÍA FEMINISTA}

La visibilización de mujeres y hombres y sus actividades y respectivos roles en el pasado, así

(1) Utilizar expresiones como arqueólogos/arqueólogas se justifica por la necesidad de hacer presentes a las mujeres. Pero los términos operan a varios niveles. La teoría del miembro marcado y no marcado y los campos semánticos negativos permitió comprender que los términos femeninos son términos marcados, que se crean por oposición a los términos masculinos, no marcados. Esto se traduce en la existencia de un campo semántico positivo para lo masculino, y un campo semántico negativo para lo femenino. Y la dicotomía no es meramente formal: los términos femeninos están sistemáticamente connotados negativamente, de forma que, por razones extralingüísticas, los términos femeninos tienden a ser despectivos, o al menos a tener significados que no son puramente descriptivos (ver Spender 1985). El uso del lenguaje es una función de las normas sociales dominantes, y aunque ciertamente tiende a reforzar dichas reglas, la separación masculino/femenino puede tener efectos contraproducentes porque implica una oposición connotada ya de antemano de una manera totalmente incontrolada por los hablantes. Quizá por ello una buena opción sería evitar el lenguaje machista utilizando términos integradores, no diferenciadores. Éste es un problema práctico que obviamente no hemos resuelto satisfactoriamente aún. como el cuidado con el lenguaje, no es infrecuente actualmente en los textos arqueológicos. Quizá no tan masivamente como sería deseable, pero la variable género se ha añadido a la práctica arqueológica general en el ámbito anglosajón y, algo menos, en España. Al menos existe una cierta conciencia de ello, producto de un cambio de actitud general en la sociedad y, directamente, de la influencia del feminismo en arqueología.

Pero existe una arqueología de género (p.e. Voss 2000; Wilkie y Howlett 2006) y una arqueología feminista. La primera es una derivación de la segunda. La arqueología del género tiene como objetivo la acumulación de una información más completa sobre el pasado añadiendo específicamente datos sobre las mujeres y sus actividades. En ese sentido, cumple en parte la ilusión de la documentación total, y es una arqueología fundamentalmente empiricista. Es en este aspecto como se ha "popularizado", relativamente.

Pero esta popularización ha tenido un precio: la arqueología del género es considerada, por parte de las autoras feministas, como un producto de la falta de compromiso político con el feminismo. A pesar de que éste constituyó el impulso necesario que puso en marcha el proceso, y de que la necesidad de "recuperar" a las mujeres en el registro arqueológico se hizo muy obvia, pocas mujeres (y hombres, por descontado) se identificaron como feministas o reconocieron una inspiración directa en el feminismo político o académico (p.e. Wylie 1996, 1997, 2001; Hanen y Kelley 1992). Por el contrario, se produjo un distanciamiento bastante extendido respecto al activismo feminista, que ha ido creciendo con los años (Engelstad 2007).

El "género", con una importante carga teórica inicial (Hernando 2007) porque implicaba no solamente una diferenciación de sexo, sino un acceso diferencial al poder social en función de él (y su uso implicaba, de paso, una fuerte crítica del orden patriarcal al poner de relieve esa desigualdad), se reconvirtió hacia un concepto neutro, ateórico. Y aunque la arqueología del género se suele caracterizar por su compromiso en la observación de los individuos -hombres y mujerescomo agentes activos, su foco central es, en realidad, su voluntad de distanciamiento del feminismo, que se percibe como una especie de guetto excesivamente politizado, y por lo tanto peligroso y comprometedor para el futuro profesional de las personas que lo reivindican (Conkey 2005a; 
Engelstad 2007) (2). En este sentido, los temas básicos de la arqueología de género -voluntad de formar parte de la arqueología "general", de ser objetiva y sobre todo, de no hacer ni parecer política-, constituyen un programa político en sí mismo.

Estrictamente hablando, por lo tanto, la arqueología del género no es un precedente lógico e histórico de la arqueología feminista, sino su versión "reducida", a pesar de revisiones a posteriori que la consideran una creación original inherentemente posprocesual porque se ocupa de individuos o agentes sociales activos (Díaz Andreu 2005: 16-17). De hecho, las arqueólogas feministas criticaron desde muy temprano este tipo de arqueología de género (Conkey y Gero 1991; Conkey 1993; Conkey y Gero 1997), precisamente porque el empiricismo no iba acompañado de compromiso teórico (p.e. Conkey y Gero 1997; Bender 2000; Conkey 2003; Engelstad 2007). Las feministas negaron la validez de un tratamiento del género que podía ser utilizado "1. allowing feminist-like scholarship to be reduced or contained as 'just another approach', with gender as 'just another variable'; or 2. (...) yet another avenue for the commodification of knowledge -for adding gender to textbooks, as just another topical speciality, or for making careers" (Conkey 1993: 8).

Esta reacción está justificada. El feminismo quería no solamente visibilizar mujeres, sino reconfigurar la manera de hacer arqueología, creando nuevos problemas a través de la reconsideración del papel del investigador en la red que forman la teoría, los datos y la práctica arqueológica (Conkey y Gero 1997: 424). Todo ello es lo que la arqueología del género no hace: no puede subvertir el paradigma dominante porque depende totalmente de él (Roberts 1993; Conkey y Gero 1997: 423).

La arqueología del género, aparentemente libre de connotaciones políticas, pretendía ganar en neutralidad y objetividad. El resultado ha sido una relativa buena (o al menos mejor) cantidad de evidencia empírica sobre mujeres en el pasado, y un debilitamiento del proyecto feminista inicial: la reivindicación de la igualdad de mujeres y

(2) Algunos ejemplos de este alejamiento de la arqueología feminista son Nelson (1997), Gilchrist (1999), Hays-Gilpin y Whitley (1998), Sørensen (2000), Díaz Andreu (2005) (ver también Engelstad 2007). hombres, y sobre todo, de renovación epistemológica (p.e. Conkey y Spector 1984; Conkey y Gero 1991; Conkey y Gero 1997, Wylie 1997, Engelstad 2007).

\section{PLANTEAMIENTOS FEMINISTAS INICIALES}

El programa feminista era fundamentalmente radical: el feminismo “(...) encompasses issues that engage us in debates about the very nature of humankind: essentialism, inequality and power relationships, social categorization, political economy, rationality and ways of knowing, ideology, meaning and symbol making, materiality and agency. Most or all of these are crucial to the archaeological enterprise, whether focused on gender or not, and often offer radically innovative twists and challenges to the ways in which our conventional categories operate" (Conkey y Gero 1997: 426). Su objetivo era indagar en las implicaciones y los supuestos que funcionan a todos los niveles en la construcción de las preguntas, las hipótesis y los resultados científicos. Los ejemplos de la necesidad de esta práctica crítica son abundantes y conocidos.

Por ejemplo, adoptar un punto de vista que observa a la historia como un proceso activo, dirigido por personas que toman decisiones conscientes para conseguir objetivos a largo plazo, o uno en el que las decisiones individuales no son consideradas un factor explicativo; o dar prioridad a la tecnología y el medio ambiente como factores explicativos de la historia (Conkey 1993: 11), son posiciones con implicaciones claras. Puntos de vista aparentemente inocuos sitúan a la investigación, de entrada, en términos ideológicos cuyos orígenes o implicaciones pueden no ser perceptibles u obvios, y por ello es necesario su análisis.

Las implicaciones, por otro lado, son siempre políticas. Y como es natural el feminismo es una empresa eminentemente política. El análisis debe estar orientado, primordialmente, a poner de relieve la marginalidad con la que la mujer ha sido tratada en los estudios científicos y en la academia.

Pero, ante todo, el feminismo es un pensamiento crítico, con fuertes implicaciones en la comprensión de la ciencia en general. Observar la práctica feminista implica al mismo tiempo observar la naturaleza de la práctica científica 
(Harding 1986, 1987, 1991; Keohane, Rosaldo y Gelpi 1982; Fox Keller 1982 y 1985; Longino 1990; Wylie 1994, 1997; Gregory y Longino 1997; Creager, Lunbeck y Schiebinger 2001) propia del proyecto de la modernidad. No por casualidad es la filosofía de la ciencia, junto con la antropología (Shapiro 1981; Moore 1988; del Valle 1993; di Leonardo 1991; ver Conkey y Gero 1991), la que en los orígenes y ahora ha tenido una mayor influencia en la arqueología feminista anglosajona.

Probablemente es en el debate sobre cómo se debe reconfigurar la ciencia, e incluso si es posible hacerlo, en el que el feminismo académico ha producido sus resultados más brillantes (Harding 1987: 3 y ss). Por ello, el papel del feminismo dentro de la teoría arqueológica debe ser adecuadamente valorado: que el registro arqueológico se forma a través de un discurso de género propio de la sociedad estudiada, y el estudio arqueológico se forma a través de nuestra propia, interiorizada y normalmente inconsciente, ideología de género, son premisas aceptadas hoy en la práctica arqueológica, independientemente del punto de vista teórico aplicado. En ese sentido, el feminismo como palanca crítica no tiene marcha atrás, y, además de contribuir a visibilizar a las mujeres en el pasado y en el presente, su reflexión ha tenido una importante influencia en la formación de otros pensamientos/arqueologías críticas.

\section{HISTORIOGRAFÍA}

Aunque algunos trabajos habían intentado reinterpretar el registro arqueológico poniendo de relieve el papel de las mujeres en el pasado (Alberts y Medicine 1983; ver Conkey y Spector 1984; Wilkie y Howlett 2006), el feminismo fue introducido oficialmente en arqueología (Preucel 1995: 155; Voss 2000: 181; Wylie 1992: 15 y 2001: 24) por Conkey y Spector (1984).

Estas autoras, basándose en gran medida en la antropología feminista, que ya existía, y en estudios feministas generales, plantearon la necesidad de, por una parte, empezar a considerar la existencia de las mujeres como sujetos históricos, de forma que la interpretación del pasado debía ser informada también por el género; por otra parte, de cumplir con los objetivos de un pensamiento verdaderamente feminista. Con su crítica al sesgo machista que caracteriza(ba) la práctica arqueológica, el artículo de Conkey y Spector fue un punto de inflexión que llevó eventualmente a la crítica de categorías eurocéntricas que habían sido consustanciales a las interpretaciones arqueológicas.

El razonamiento más básico detrás de esta crítica es que la revisión de las categorías heredadas debía tener consecuencias necesarias en el presente. Y la más obvia de ellas era que las relaciones desiguales entre sexos tienen historia; no son naturales. Esto llevaría a una reconsideración de estas relaciones de género en la actualidad.

La determinación de influir en el presente era, obviamente, uno de los pilares del programa feminista. Y a pesar del distanciamiento respecto del feminismo que se produjo muy pronto, un número creciente de mujeres de cualquier signo político tenían una clara percepción de la desigualdad entre mujeres y hombres, y especialmente en su contexto más inmediato, dentro de la propia academia (Gero 1983 y 1985; Wylie 1996, 1997, 2001; Nelson, Nelson y Wylie 1994; Smith y du Cros 1995; Hanen y Kelley 1992) (3).

Ésta puede ser una de las razones, junto con la fuerza del feminismo en política y en las ciencias sociales, por las cuales el género como objeto de estudio arqueológico creció muy deprisa (Wylie 1992: 16; 1997: 91 y ss; 2001: 25 y ss). En Noruega y Gran Bretaña hubo pronto congresos y sesiones en congresos (en 1979, 1982, 1985 y 1987), en 1985 se fundó la revista K.A.N. Kvinner $i$ arkeologi $i$ Norge (K.A.N. Mujeres en arqueología en Noruega) (Engelstad 2007), y en 1988 empezaron coloquios sobre el género en los congresos de la Society for Historical Archaeology (Conkey y Gero 1997; Wylie 1997 y 2001). El Archaeological Review from Cambridge editado por Karen Arnold, Roberta Gilchrist, Pam Graves y Sarah Taylor en 1988 fue dedicado a Women in Archaeology (Arnold et al. 1988). Y, fundamental en este contexto de ebullición feminista de finales de los años 80, es la Wedge Conference organizada por Margaret Conkey y Joan Gero en 1988, quienes quisieron activar definitivamente el interés por el estudio de las mujeres "encargando" una serie de trabajos que realizaran el programa

(3) Los trabajos de sociología de la ciencia siguen poniendo de relieve la posición de inferioridad de las mujeres en la Academia, en todos los ámbitos científicos (por ejemplo, Loder 2000; VVAA 2000; ver también la información recopilada por la Asociación de Mujeres Investigadoras y Tecnólogas, http://www.amit-es.org/publicaciones.htm). 
que Conkey y Spector (1984) habían propuesto (Wylie 1992: 15).

El congreso produjo Engendering Archaeology: Women and Prehistory (Gero y Conkey 1991), un libro muy influyente en la arqueología feminista, que atacaba tres frentes principales: el sesgo machista de la investigación arqueológica en todos sus aspectos, la falta de materialización de las mujeres y su participación social en el pasado, y los supuestos no reflexivos sobre el género y la diferencia (Conkey y Gero 1991: 5). Además, en 1989 tuvo lugar una sesión sobre género y arqueología en el congreso de la Society for American Archaeology y la Chacmool Conference de la Universidad de Calgary (Walde y Willows 1991).

En estos años se publicaron otros volúmenes monográficos (Miller 1988; Ehrenberg 1989; Seifert 1991; Claassen 1992; Scott 1994a; Wall 1994). En 1991 Elizabeth Brumfiel fue la Distinguished Archaeology Speaker en el congreso de la American Anthropological Association (Brumfiel 1992). En esta conferencia, Brumfiel mostró que el tratamiento del género, junto con la clase y la facción, era en realidad un reto al paradigma dominante, la teoría de sistemas. Gero (1993) conectó por primera vez la realidad de la sociología de la investigación dedicada a la etapa paleoindia en Estados Unidos, dominada por hombres que se citan entre sí y mujeres dedicadas a la investigación de asuntos "menores", con el propio contenido de esa investigación, que, no muy sorprendentemente, se focalizaba en las actividades cazadoras consideradas masculinas y toda una supuesta dinámica social relacionada con ellas.

Otros trabajos, que se citan recurrentemente al rehacer la historia de la arqueología feminista, son (para mayor exhaustividad ver Conkey y Gero 1997), entre otros, Claassen (1991), Pollock (1991), Du Cros y Smith (1993), Spector (1993), Gilchrist (1994) y, especialmente, Brumfiel (1991), Hastorf (1991), Spector (1991) y Watson y Kennedy (1991) [todos en Gero y Conkey 1991 (4)]. Se trata de casos específicos de estudio sobre los que se producen hipótesis y datos sobre roles de mujeres y, por extensión, procedimientos por los cuales la arqueología feminista debe de-

(4) "possibly the most influential book published on archaeological theory in the last decade" (M. Johnson citado en Conkey 2005a: 55). sarrollar su programa. En este sentido, en estos estudios se aprende a hacer una arqueología feminista. Además no se limitan a materializar a las mujeres proyectando concepciones contemporáneas hacia el pasado, sino que buscan variabilidad sobre la función y la representatividad social de las mujeres a lo largo del tiempo, ayudando así a construir conceptos de género dinámicos e históricos (Conkey y Gero 1991).

Más recientemente, la producción bibliográfica se ha multiplicado y diversificado enormemente, incluyendo tanto trabajos de contenido ligado al género, como revisiones historiográficas (Balme y Beck 1995; Conkey y Tringham 1995; Claassen y Joyce 1997; Gilchrist 1999; Joyce 2000; Conkey 2003; Conkey 2005a; Wilkie y Howlett 2006; Nelson 2006, Nelson 2007, Joyce 2007; Gilchrist 2007, entre muchas otras), biografías (Bender 1991; Cordell 1991; Nelson 1991; Levine 1991; Claassen 1994; Reyman 1992; Parezo 1993; Díaz Andreu y Sørensen 1998), tecnología y análisis ideológicos (en Wright 1996), o la enseñanza de la arqueología y la presentación del pasado (Claassen 1992; Gifford-González 1993; Conkey y Tringham 1996; Romanowicz y Wright 1996; Conkey 1991, 1995 y 1997; Wiber 1997; Moser 1998; Joyce, Guyer y Joyce 2000).

En España, la teoría y práctica arqueológicas tradicionales no se han visto excesivamente amenazadas por el feminismo. Como en otros lugares, el feminismo se ha desarrollado sobre todo en foros propios (ver Conkey 2007 para el caso anglosajón). Pero el feminismo español tiene consistencia y existencia propias, contrariamente a lo que ocurre con otros enfoques teóricos en nuestro panorama académico (algo muy notable, dada la tradicional escasez de teorización de la arqueología española).

Probablemente por la relación de ciertas investigadoras con el feminismo político y académico (por ejemplo, M.E. Sanahuja), el feminismo apareció en la arqueología española (sobre todo en Cataluña), prácticamente al mismo tiempo que en la escandinava y en la estadounidense. Desde principios de los años 80 se han hecho ciclos de estudios y seminarios sobre mujeres, división sexual del trabajo y discurso científico feminista.

La Reunión de Arqueología Teórica (RAT) celebrada en la Universidad de Santiago de Compostela en 1992 recogió una sesión titulada "Arqueología de las mujeres", en la que participaron 
E. Sanahuja, M. Picazo, S. Gili, P. González, S. Montón, C. Rihuete, E. Colomer, C. Álvarez, M.J. Bóveda, C. Sánchez-Albornoz, L. Vilaseco, A. Vila, T. Argèles, N. Sanz, M. Díaz Andreu, M. Parra, T. Sanz y M. Tenas. Esto da cuenta de cierta relevancia que ya entonces la arqueología feminista tenía en España. Los encuentros, sesiones, mesas redondas, seminarios, asignaturas y cursos de doctorado sobre Arqueología y Género han sido relativamente frecuentes desde entonces (ver Díaz Andreu 2005: 21-22), y hay que destacar especialmente los congresos celebrados en Granada en los años 2003 (Sánchez Romero 2005) y 2005 (Sánchez Romero 2007).

La arqueología feminista anglosajona ha ejercido cierta influencia en la española, el mejor ejemplo de lo cual es el volumen compilado por Colomer et al. (1999), con traducciones de J. Gero (1985), M. Conkey y R. Tringham (1996), A. Wylie (1992), J. Spector (1991) y R. Tringham (1991), entre otras. También parece haber tenido algún impacto el trabajo de la antropóloga feminista Henrietta Moore (1988, traducción de 1999). Hay algunos temas que han tenido cierta popularidad, en algún caso por influencia anglosajona: biografías de arqueólogas (Díaz Andreu y Sanz 1994; Baquedano 1993; Álvarez 1997; Díaz Andreu 1998; Cárdaba et al. 1998; San Clemente 1998), revisiones críticas sobre la narrativa del origen y la evolución humana (Sanahuja 1991; Querol 2001 y 2005a; Querol y Treviño 2004), sobre la representación de la mujer en el pasado (Díaz Andreu 1998b; Querol 2000; Sánchez Liranzo 2005a; Hornos y Rísquez 2005) $\mathrm{y}$, recientemente, una historia de las mujeres (Chapa 2005; Hernando 2005a; Querol 2005b).

Pero el grueso de la arqueología feminista en España parece haber recibido, en general, influencias más heterogéneas y variadas de lo que ha sucedido con la arqueología feminista anglosajona: aparte de la influencia de esta última, de entre las tradiciones filosóficas europeas destacan el marxismo y el estructuralismo, y el psicoanálisis (Picazo 1997; Sanahuja 1997a y 1997b, 2001, 2002; Castro et al. 1998; Hernando 2000a, 2000b, 2003, 2005b; Balaguer y Oliart 2003; Escoriza 2002; Castro et al. 2003; Escoriza y Sanahuja 2005). Las implicaciones epistemológicas de la práctica y la ciencia feministas, que la arqueología anglosajona ha tratado extensamente (ver más abajo), están aún relativamente poco desarrolladas en España (pero ver Colomer et al.
1999; González 2000 y 2005; González y Picazo 2005; Sánchez Liranzo 2005b; Fernández 2006).

\section{FEMINISMOS}

Esta pequeña historiografía, anglosajona y española, no es más que un resumen de la producción de las dos últimas décadas. El discurso feminista es múltiple, teórica y metodológicamente (Conkey 1993; Conkey y Gero 1997). La arqueología feminista acoge, de hecho, puntos de vista contradictorios. Por ejemplo, según Conkey y Gero (1997: 412), las seis principales aproximaciones teóricas al género incluyen la sociobiológica, el género como construcción social, el género como proceso evolutivo, el género como economía política, el género como agencia y el género como "actuación" (performance) (Scott 1986; Conkey y Gero 1997: 416-421).

La contradicción básica entre algunas de estas posturas está en el tratamiento del género como una realidad biológica, universal, esencial, o bien como una construcción social, histórica. Simplificando algo el problema, se puede proponer que ésta es la dicotomía fundamental que aflora en términos de feminismo de la diferencia $v s$. feminismo de la igualdad (ver, por ejemplo, Amorós y de Miguel 2005), mientras que en el ámbito anglosajón esta oposición se ha formulado más bien como feminismo de "tercera ola".

En cualquier caso, el impacto de este debate ha sido muy fuerte en el desarrollo del pensamiento feminista general, no solamente arqueológico. Junto con el problema de la posibilidad o imposibilidad del "feminismo científico", constituye seguramente el debate fundamental de lo que debe entenderse como feminismo: si algo ha hecho el feminismo, precisamente, es reconvertir la categoría "género" de concepto natural de sentido común, hacia una cuestión abierta, a analizar, haciendo hincapié en la naturaleza relacional de la asignación cultural de los roles de género (Scott 1994b: 10; Hernando 2008). Esta, ahora obvia, hazaña intelectual ha sido, curiosamente, muchas veces mistificada por las propias mujeres en los debates sobre la diferencia.

Como introducción sintética a los debates feministas en la arqueología podemos utilizar la distinción de Preucel (1995: 156), en tres corrientes feministas: 1) el "feminismo analítico", que se ocuparía de buscar mujeres en el pasado dentro 
de los parámetros marcados por la ciencia; 2) el "feminismo hermenéutico", que considera que la ciencia se ha constituido exclusivamente sobre la experiencia masculina y reclama una ciencia que introduzca la experiencia femenina (5), y 3) el "feminismo crítico", que intenta poner de manifiesto el sesgo machista en el presente, especialmente dentro del mundo de la academia, con el objetivo, por supuesto, de reequilibrar las relaciones de poder existentes. Este tipo de investigación ha puesto de relieve las arbitrariedades que las mujeres sufren en términos de visibilización -y muchas veces de financiación-.

La cuestión de fondo aquí es hasta qué punto es posible reconducir la práctica científica para convertirla en una herramienta crítica que permita comprender la realidad y cambiarla, manteniéndose al mismo tiempo dentro de los parámetros de lo que significa convencionalmente hacer ciencia, o por el contrario, si hay una metodología y epistemologías específicamente feministas (Harding 1987: 1-13); una tercera opción es considerar a la ciencia como un proyecto fundamentalmente constituido sobre la desigualdad y la creencia metafísica en la objetividad y la verdad (como propone el posmodernismo), lo cual convertiría a la ciencia feminista en una contradicción in terminis.

De hecho, otra forma de plantear este problema es determinar la relación entre el feminismo y la filosofía posmodernista. Los críticos del feminismo tienden a incluir el primero en el segundo, porque, al cuestionar los principios epistemológicos de la ciencia occidental, el feminismo ha sido acusado de relativista. Hay, ciertamente, una corriente feminista posmodernista (Harding 1987: 187 y ss.) (6). Sin embargo, el feminismo rechaza mayoritariamente su equiparación con el posmodernismo (Hawkesworth 1989; Mascia-Lees et al. 1989; Wolff 1990; Engelstad 2007), y en arqueología el feminismo se ha distanciado casi

(5) El "feminismo analítico" y el "feminismo hermenéutico" corresponden en realidad a dos puntos de vista habituales en ciencias sociales, el feminismo empirista y el "punto de vista feminista" (feminist standpoint) (Harding 1987).

(6) Agradezco a Almudena Hernando la información y referencias sobre el concepto de interseccionalidad (Mahmood 2001; Pattyname 2006; Davis 2008), originado por la crítica de las feministas negras (Crenshaw 1989) al feminismo clásico, considerado eurocéntrico por no haber tenido en cuenta factores como la raza o la clase al analizar la opresión de la mujer. Esta perspectiva se está adaptando en arqueología como parte de la arqueología posmoderna en sentido amplio. totalmente del constructivismo posprocesual (Conkey 1993: 9; Wylie 1996: 312).

$\mathrm{Y}$ es que el feminismo se ha visto atrapado en un dilema conocido: por una parte, la necesidad de efectuar una crítica radical a la forma occidental de producir conocimiento; por otra, la obligación, impuesta por motivos prácticos, de mantenerse dentro de ese sistema de conocimiento, por dos razones: una, la de producir conocimiento preciso sobre la realidad, válido y de carácter intersubjetivo, que eventualmente permita actuar sobre esa realidad; dos, la de jugar un papel de cambio social manteniendo una voz dentro del sistema científico (7). Entre estas posturas, las feministas han elegido, mayoritariamente, mantenerse dentro de la estructura científica.

\section{EL FEMINISMO COMO EMPRESA CIENTÍFICA}

A pesar de que la crítica posprocesual fue muy clara en cuanto a la subjetividad del conocimiento que los arqueólogos estaban produciendo, las implicaciones políticas y sociales de la teoría de sistemas o del difusionismo no son necesariamente inmediatamente obvias. Un estudio ar-

(7) " $\ldots$ the development of structuralist and post-structuralist theory, hermeneutics, and the sociology of knowledge in recent decades has rendered impossible the retention of the view of science and knowledge which has lasted from the Enlightenment to Modernism, and which is founded on a faith in the uniformity of science and the possibility of a transcendent objectivity. In the late twentieth century we know that all knowledge is socially and historically located (and therefore partial), and that any theory is a product of (and limited by) language and discourse.

However (...) there is a certain inconsistency in this position. It has been argued that Lyotard's critique of theory is itself (necessarily) founded on theory. Feminist postmodernism faces the same dilemma, because the deconstructive strategies of postmodern cultural practice, or of epistemological critique, depend on the theory of feminism -the articulated argument that society is structured around sexual inequality. Acknowledging this, Sandra Harding proposes replacing a confidently universal theory with a limited, provisional 'successor science'. Nancy Fraser and Linda Nicholson have recently argued for the retention of 'large narratives', and for a postmodern-feminist theory which would be 'pragmatic and fallibilistic'. But it has to be said that resolutions to this dilemma to date are mainly pragmatic. The epistemological paradox remains, and it may be that the justification of new critical theories can only be made on other, non-epistemological, grounds, including those of usefulness (one theory explains more of the world than another), politics (acknowledged commitment to a point of view), or self-reflexive provisionality (admission that this theory, though valuably deconstructive of dominant discourses, is itself open to such deconstruction)" (Wolff 1990: 89). 
queológico producido en esos marcos teóricos puede ser observado como una reproducción inconsciente del paradigma dominante y de sus principios metafísicos (racionalidad, objetividad, neutralidad). Pero pocas veces se observará como una forma de perpetuar un presente socialmente injusto.

Sin embargo, la negación sistemática de la presencia de las mujeres, tanto en el proceso de producción de conocimiento arqueológico como en los productos de dicho proceso, es una clara proyección de la presente discriminación social de la mujer hacia la práctica arqueológica. Este desequilibrio entre sexos en todos los aspectos de la actividad arqueológica se puede intentar justificar como una consecuencia de la falta de resolución del registro, por ejemplo, o como una consecuencia de la falta de acceso a la educación por parte de las mujeres de generaciones precedentes, o se puede intentar minimizar rechazando al mismo tiempo el feminismo por "relativista" o "radical" (Patai y Koertge 1994, en Conkey y Gero 1997). Pero difícilmente se puede negar seriamente a estas alturas. La arqueología como disciplina ya no es inocente en este sentido, y por lo tanto tampoco lo son sus practicantes.

El feminismo, mucho más que otros tipos de análisis, ha hecho clara la inevitable implicación social de la arqueología, y su carácter de construcción social. O, en otros términos, que la ideología afecta directamente a la construcción de hipótesis y a los resultados. La "ciencia neutral", por lo tanto, es un sistema de conocimiento que refleja la estructura social y sobre todo la justifica, siendo así una importante herramienta en el mantenimiento de la organización política vigente.

El feminismo académico se presentó como una plataforma desde la que reconfigurar esta "ciencia neutral", deconstruyendo las estructuras de poder heredadas a través de una posición política fuerte. Esto inevitablemente planteaba la cuestión de cómo se produce ese conocimiento, y de su validez. A partir del problema de si es posible producir conocimiento válido intersubjetivamente sobre las bases de una postura inicial políticamente comprometida, el feminismo realizó una crítica consistente a la epistemología tradicional. En pocas palabras, el feminismo cuestionó que el contexto en el que las preguntas o las hipótesis se formulan originalmente ("contexto de descubrimiento") sea irrelevante para las pro- pias preguntas o las respuestas que se obtienen ("contexto de justificación") (Harding 1987: 7 y 183).

El feminismo demostró que las preguntas que la ciencia plantea no son inocentes; tanto las preguntas como sus respuestas han sido exclusivamente las que han producido los hombres blancos occidentales de clase media-alta en función de sus intereses propios (Harding 1987: 6 y ss.; Hartsock 1986, 1987). Las teóricas del "punto de vista feminista" (feminist standpoint) (N. Hartsock, S. Harding, entre otras) propusieron que las experiencias de las mujeres, comprometidas en la lucha política por la igualdad, deben reconfigurar la epistemología tradicional (Harding 1986, 1987: 185 y ss.; Hartsock 1987), porque la ciencia se hace por alguien, por algo y para algo. Las experiencias de las mujeres como sujetos oprimidos crean la necesidad de cuestionar la ciencia, pero ello no significa que un punto de vista feminista sea natural o exclusivo de las mujeres. Un punto de vista feminista no se tiene; se construye (Harding 1987: 185) (8).

Esta investigación políticamente comprometida puede, sin embargo, producir análisis mejores (Harding 1987: 9 y 187), básicamente no reproduciendo los estereotipos heredados, ejerciendo la crítica y la reflexión de todos los criterios y conceptos más "naturales" o de sentido común, y al mismo tiempo situando al investigador en la realidad social que lo constituye y en el mismo plano respecto a sus objetos de estudio.

La arqueología hizo una versión simplificada de todo ello, ya que no es en su campo donde se han dirimido las principales cuestiones. El feminismo más representativo en la arqueología no niega la ciencia ni su validez, sino que pretende consolidar su "objetividad" poniendo atención a cómo se construye [Wylie (9) 1992: 16; Wylie 2002].

Esta reivindicación, sin embargo, ha sido larga y trabajosa, porque el feminismo, con su crítica al objetivismo, fue asociado con el hiperrelativismo posmoderno y observado con escepticismo

(8) "The questions we ask about the past are rooted in the present, and it cannot be otherwise; we therefore have the responsibility to be aware of whom our research serves" (Scott 1994: 14).

(9) Alison Wylie es filósofa de la ciencia. Uno de sus principales objetos de estudio ha sido el feminismo, la generación del conocimiento arqueológico y la relación entre ambos. Wylie ha contribuido enormemente al desarrollo de las cuestiones epistemológicas en la arqueología feminista. 
(Wylie 1997: 85). Como las propias feministas han demostrado, esa asociación no estaba libre de tendenciosidad.

La arqueología feminista se realiza verdaderamente en el propio proceso de producir conocimiento científico (Conkey y Gero 1997: 430431), y explícitamente tiende hacia la objetividad desde una perspectiva parcial y concreta, desde una posición específica que asume su subjetividad como una característica inherente al conocimiento científico (Wylie 1992, 1994, 1996, 1997, 2002; Engelstad 1991), no como una práctica perversa que es necesario evitar. Por ello, el feminismo aboga por la aplicación de un razonamiento riguroso en cada paso que damos en la construcción de nuestras inferencias, haciendo modelos científicos explicativos sólidos y justificados.

En definitiva, nuestro posicionamiento en un punto de vista parcial es inevitable. La consecuencia que el feminismo deduce de este hecho no es que cualquier punto de vista se justifique por igual, sino que la atención a cómo se construyen los argumentos debe incrementarse, no debilitarse (Wylie 1992, 2000, 2002).

El producto de este análisis debe ser, y ha sido en muchos casos, el hacer explícitos los procesos de razonamiento y justificación y el descubrimiento de argumentos circulares. Esto supone, por tanto, una mejora en sentido general del razonamiento y la metodología arqueológicas (Wylie 2000; Conkey 2003). No sólo hay crítica, sino también interpretaciones sustantivas. Y en ellas, la aceptación de que el proceso de interpretación no está radicalmente abierto es fundamental. Los datos no se constituyen de manera arbitraria. Y aunque los valores y los intereses de los investigadores, explícitos o no, condicionan las preguntas y los métodos que emplean, siempre pueden ser discutidos conceptualmente, o no ser corroborados empíricamente (Wylie 1994, 1997).

Esta confianza en la mejora de los procesos de inferencia y en la evidencia empírica como controles de la práctica científica es propia del feminismo (Harding 1986; Wylie 1997), pero no lo es del posprocesualismo (sobre todo inicial), que tendió a rechazar el proyecto científico por considerarlo esencialmente viciado en su origen. Por lo tanto, la introducción del feminismo en arqueología es paralela a la del posmodernismo, pero es independiente en origen y en práctica (Engelstad 2007). De hecho los arqueólogos posprocesuales fueron tempranamente criticados por reproducir actitudes machistas (Engelstad 1991; Gilchrist 1992; Wylie 1992 y 1997).

La arqueología feminista es por lo tanto radical, pero no rompe con la tradición científica occidental (10). Incluso si no se pueden llegar a individualizar mujeres (u hombres) en el registro arqueológico, la aportación que una reflexión feminista puede hacer, consecuentemente con su estatus de ciencia, es producir teorías que no estén sesgadas en origen y marginalicen a las mujeres, ni estén basadas en categorías aparentemente naturales (como la maternidad), que son fruto de una situación histórica concreta que es necesario revertir. En este contexto, los esencialismos son los enemigos del feminismo.

No es aceptable, por lo tanto, materializar arqueológicamente a las mujeres en el pasado utilizando para ello hipótesis incontrastables, construidas sobre una sola variable, sobre conceptos esencialistas, o con los mismos criterios que se habían utilizado previamente con el resultado contrario. No es aceptable ser laxo con la evidencia arqueológica para favorecer una mayor presencia de mujeres en nuestras reconstrucciones.

Antes de que la perspectiva feminista se practicara, ese tipo de razonamientos (que tendían a invisibilizar a las mujeres) se hacían de una forma "natural". Una vez en marcha la crítica, la única explicación para ese tipo de interpretaciones es la necesidad de mantener el statu quo. Y el feminismo, por un lado, sigue estando en posición de resistencia. Por otro lado, no puede permitirse la falta de reflexión sobre su práctica, y por ello ha de ser mucho más riguroso, aunque ello suponga no poder "rellenar huecos" (ni sustituir una narrativa androcéntrica con una ginocéntrica) (Conkey y Tringham 1995 y 1998; Conkey 2003).

(10) Little considera que la arqueología feminista es radical pero también conservadora: "The feminist critique adopted in Wylie's defense of feminist research in archaeology and in Keller's historical tracing of the defeat of hermaphroditic science is both radical and conservative. It is radical in its poststructural and postmodern rejection of the meta-narrative that supports Western gender ideology-including the metaphorical dichotomous structure of ways of knowing. On the other hand, it is conservative in retaining faith in the possibility of knowledge, even if that knowledge is never finalized. A feminist critique of archaeology that creates a mediating approach will seek to restore connections. This feminism aims at creating a better science, that is, a more encompassing and intricate science that recognizes contexts, contingencies, and ambiguities" (Little 1994: 543) (ver también Fotiadis 1994, ambos desde un punto de vista no posmoderno). 
La demostración consistente de la invisibilización de las mujeres, y su explicación, es un resultado bueno en sí mismo. Es preferible también hacer explícito que no se va a cualificar en términos de sexo una interpretación dada, por no ser el trabajo arqueológico adecuadamente resolutivo, por ejemplo, que añadir roles femeninos de manera acrítica. De esta manera, el feminismo cumple por una parte su programa crítico y, por otra, sitúa la carga de la prueba en las interpretaciones que asignan roles masculinos "por defecto". La excesiva presencia del género - masculino-en las interpretaciones arqueológicas, señalada ya por Conkey y Spector (1984) y Conkey (1993), debe tratarse como un defecto de la investigación, que deben solucionar los arqueólogos que aún lo cometen.

Una síntesis de los logros del feminismo en la arqueología, según Wylie (2001: 35 y ss.) y Conkey (2005a: 58 y ss.) se puede enumerar como 1) documentación de actividades asociadas con mujeres, a microescala y en la vida cotidiana, que tradicionalmente se consideraban poco accesibles arqueológicamente; 2) gran desarrollo de la investigación sobre restos humanos, en busca de diferencias en la dieta y en el trabajo en función del sexo y la edad; 3) miradas nuevas y productivas sobre conjuntos arqueológicos previamente estudiados y aparentemente bien entendidos, para los que se han empleado otras estrategias de análisis, a menudo basadas en investigación etnográfica, etnoarqueológica y de arqueología experimental; 4) replanteamiento de los grandes modelos explicativos del pasado, desde el punto de vista de la existencia de roles de género que se constituyen específica e históricamente en las sociedades estudiadas; el género se observa como una categoría mutable, no necesariamente constituida sobre la distinción biológica entre sexos, lo cual implica la contingencia de nuestra estructura social; 5) llamadas de atención sobre la contingencia y falta de viabilidad de gran parte del pensamiento arqueológico tradicional, incompleto, sesgado y, por tanto, escasamente explicativo; 6) puesta en práctica de formas menos jerárquicas de organización del trabajo arqueológico, incluyendo comunidades ajenas a la academia, y de prácticas pedagógicas alternativas, y 7) creación de un interés por procesos sociales más generales, como la multidimensionalidad de la identidad y la posición social. En definitiva, el feminismo no ha sido una exploración de formas distintas de hacer y presentar la arqueología y su impacto en el presente.

Pero aún hay otros ámbitos en los que el feminismo tiene mucho que conseguir, según Conkey y Gero (1997: 429): 1) en el incremento del reconocimiento de la subjetividad humana en la producción del conocimiento: las decisiones tomadas en cada momento han de ser conscientes y transparentes, sobre todo en relación con valores y prioridades personales y sociales; 2) en la organización de proyectos de campo arqueológicos menos jerárquicos, y más democráticos, que den cabida a múltiples interpretaciones y evaluaciones en cada paso irreversible de la investigación, y a la coordinación de múltiples estrategias y objetivos por distintos investigadores, y 3 ) en la aceptación de la parcialidad del conocimiento arqueológico (ver también González 2005).

Los argumentos de autoridad son todavía demasiado frecuentes. Y aunque la crítica de este aspecto en particular, y de otros, de nuestra práctica arqueológica, no sea patrimonio exclusivo del feminismo, forma claramente parte de su universo. En este sentido, no hace falta identificarse como feminista para abordar muchos de los problemas estructurales que tenemos. Así, por una parte, el programa feminista puede latir en muchas áreas sin hacerse explícito. Pero, por otra parte, el feminismo "pasa desapercibido" y sigue académicamente marginalizado en foros propios. Este efecto no es necesariamente beneficioso para las mujeres, dada la ingente acción política que aún es necesaria en la arqueología como disciplina y en la sociedad.

\section{VÍNCULOS DEL FEMINISMO}

En definitiva, el feminismo demuestra que una posición política fuerte como punto de partida no implica la producción de interpretaciones forzadas. Al contrario, la ciencia políticamente comprometida puede ser más rigurosa, auto-crítica y consistente con los datos, que la ciencia considerada neutral (Harding 1987: 182; Wylie 1992: 30, 1997: 98-99). A pesar de que sea la experiencia personal la que movilice el interés por un tipo de investigación específica (algo que sucede con cualquier objeto de estudio), el salto entre el presente (desigual) y las inferencias sobre el pasado tiene que cubrirse con un procedimiento científico como el que se ha explicado: la reflexión sobre 
todas y cada una de las categorías que se utilizan debe ser permanente; dichas categorías han de ser tratadas como aptas para un determinado análisis después de ser justificadas.

Como es evidente, el programa crítico feminista no tiene límites. Una vez aislado el sesgo machista, el análisis se extiende a cualquier otro sesgo consciente o inconsciente que afecte a la práctica científica, como por ejemplo esencializar la condición de "la mujer", tratándola como un sujeto ajeno a categorizaciones sociales distintas de la de género, como la cultura, la raza, la clase y la orientación sexual (Harding 1987: 188 y ss.; Hartsock 1987; Hill Collins 1989; Pattyname 2006). Algunos trabajos en este sentido para la arqueología histórica se recogen en Wilkie y Howlett (2006: 249). La llamada queer archaeology es paradigmática en este sentido.

La queer archaeology es una contestación a la equiparación género-sexo que hacía el feminismo, que, ocupado en desarrollar estudios de género, no se ocupó al mismo tiempo de deconstruir esta categoría (Voss 2000: 186). Y en este sentido, la queer archaeology es básicamente un desarrollo crítico sobre el feminismo (pero ver Voss 2000: 184-185, que considera que ambas tienen desarrollos paralelos pero independientes). Lo más específico en lo queer es la sexualidad y su papel en la construcción de los roles de género; su objeto es pues más limitado que el del feminismo (y probablemente menos accesible arqueológicamente) (Schmidt y Voss 2000; ver también Meskell 1999 y 2002; Joyce 2000 y 2007; Meskell y Joyce 2003).

En relación con la necesidad de resituar el feminismo, me interesa especialmente destacar su relación con el marxismo. Históricamente, y a pesar de una relación amor-odio conocida -por ejemplo en torno a la discusión sobre la opresión de las mujeres a través de relaciones de clase o de estatus-, el feminismo, en una parte importante, se basa en la epistemología marxista (Harding 1987: 185; Hartsock 1987). Esta asociación es consistente además en las ciencias sociales [Haug 1983; Strathern 1983; Leacock 1972 (en Moore 1988 [1999]), 1978; Sacks 1974, 1976; de Miguel 1993] (11).

(11) Es conocida la analogía de Engels en El origen de la familia, la propiedad privada y el Estado: "El hombre es en la familia el burgués; la mujer representa en ella al proletario". Esto está en el núcleo de la cuestión sobre si la opresión de las mujeres es un aspecto más de la explotación capitalista o no, y si
Aparte de estas relaciones genealógicas académicas, que no podemos entrar a discutir aquí, hay una simetría muy aparente entre feminismo y marxismo. El marxismo des-esencializa cualquier categorización de la mujer que el feminismo pueda llegar a plantear. El feminismo profundiza en la comprensión de las relaciones de poder desigual dentro de cada clase o estrato social, y, sobre todo, en su constitución. Así, feminismo y marxismo, más allá de sus diferencias, establecen una relación dialéctica provechosa, situando y resituando a los actores sociales en distintos contextos, simultáneos, complementarios y contradictorios. Ambos pensamientos analizan la realidad y la ciencia en términos del origen del poder social que subyace a ellas, y conciben a la última como una forma de comprender ese poder social y la opresión que produce. Tanto la arqueología feminista como la arqueología marxista son arqueologías sociales.

La cuestión de si la desigualdad en razón del sexo (que no es necesariamente igual a división sexual del trabajo) ha existido siempre o es un producto histórico está probablemente en la base de toda la práctica feminista, y se inscribe en la cuestión más general, que está en la base de la práctica marxista, de si la jerarquía, la desigualdad y la explotación son consustanciales a la socialización humana (igual que el lenguaje) o, nuevamente, productos históricos. En este sentido, "encontrar" mujeres en el pasado es solamente una solución parcial, porque habría que definir exactamente las condiciones en las que las mujeres vivieron. Por ejemplo, determinar que las mujeres realizaban gran parte de las actividades económicas de todos los tipos no implica que las mujeres ostentaran también gran parte de la representación social y política del grupo. Puede, de hecho, implicar lo contrario. Y remitir la desigualdad a los "orígenes" naturalizándola en la diferencia física entre hombres y mujeres no ayuda, porque sitúa de antemano a hombres y mujeres como sujetos conscientes de sus especificidades individuales, implicando que la socialización se produce de forma dirigida desde la conciencia, y no al contrario. En este asunto el marxismo y el feminismo no se han entendido bien en algunas ocasiones.

no lo es, es necesaria entonces una lucha específica independiente de la lucha de clases. En cualquier caso, el capitalismo parece haber contribuido a empeorar la situación de las mujeres de forma consistente (ver, por ejemplo, Harding 1986). 
Feminismo y marxismo comparten también a veces la búsqueda de cierta legitimidad para sus reivindicaciones políticas en la demostración de que la desigualdad es un producto histórico, lo que implicaría que ha existido una formación social igualitaria, o al menos no opresora, en función de sexo y estatus. Es posible que esta demostración -arqueológica- sea difícil de sustanciar, pero evidentemente eso no significa que las reivindicaciones del presente queden desarmadas. Marxismo y feminismo tienden a la utopía (i.e. la práctica comprometida políticamente no tiene un objetivo predeterminado), se hacen en el proceso de hacerse, y sus aspiraciones son legítimas porque son justas, independientemente de cómo fuera la vida en el pasado.

La arqueología marxista feminista tiene aún un largo camino por recorrer, pero podemos destacar a Brumfiel (1992) (quien conjuga una perspectiva materialista histórica con una perspectiva posestructuralista -lo que luego será la arqueología de la agencia-), Spriggs (1993), Scott (1994a y 1994b) entre otras, y, en mi opinión, gran parte del feminismo español, con su interés por la reproducción como trabajo y el trabajo doméstico en general, y sus implicaciones sociales (Sanahuja 1997a y 1997b, 2001, 2002; Picazo 1997; Castro et al. 1998; Colomer et al. 1999; González 2000; Balaguer y Oliart 2003; Castro et al. 2003; Sánchez Liranzo 2005b), así como la Arqueología Social Latinoamericana (p.e. Vargas 2004).

\section{IMPLICACIONES DEL FEMINISMO}

El feminismo, tal y como se ha entendido en este texto, sigue estando infrarrepresentado en la mayor parte de los trabajos arqueológicos (Conkey 2003), en beneficio de su variante empirista. Pero ha tenido influencia directa o indirecta en otras arqueologías, como la queer archaeology, la arqueología de la agencia (por ejemplo, Dobres y Robb 2000), la arqueología de la identidad (por ejemplo, Hernando 2002), la arqueología de la unidad doméstica (household archaeology) (por ejemplo, Tringham 1991) y de las actividades de mantenimiento (por ejemplo, Montón et al. 2008), la arqueología de la persona (personhood archaeology) (por ejemplo, Gillespie 2000) y la arqueología del cuerpo (por ejemplo, Joyce 2005). El programa, el alcance y, por lo tanto, la relevancia de estas arqueologías, son más restringidos que los de la arqueología feminista, pero por eso resultan también más aceptables por parte de los arqueólogos.

Más importante me parece señalar la raíz común de la arqueología feminista con las que, probablemente, son las dos arqueologías contemporáneas más críticas: la arqueología indigenista (Conkey 2005b), y la arqueología poscolonial (Wylie 1997; Bray 2005) (la relación entre feminismo y poscolonialismo es consistente a través de las disciplinas; por ejemplo, Harding 1998). El activismo político que subyace a todas estas formas de producir arqueología es similar: se trata de dar una contrapartida crítica a la arqueología tradicional producida por hombres blancos occidentales de clase media-alta. La necesidad de producir un conocimiento que ponga en entredicho la estructura de poder heredada es el eje en el que la arqueología feminista y otras arqueologías "marginales" se cruzan (Conkey 2005b).

Dicho todo esto, no deja de ser paradójico que el grueso de lo que se puede citar en relación con el feminismo, el indigenismo y el poscolonialismo en arqueología proceda de la bibliografía anglosajona. Mi propio discurso en este texto es paralelo al desarrollo anglosajón de la arqueología feminista, exportada a otras tradiciones arqueológicas (como había ocurrido con otras corrientes críticas y renovadoras: Nueva Arqueología y posprocesualismo en especial).

En este sentido, el pensamiento crítico que el feminismo quiere introducir y la falta de permeabilidad de la arqueología anglosajona a cualquier influencia procedente de otras tradiciones de pensamiento son incompatibles. Incluso se puede considerar una nueva forma de imperialismo, contradictoria con las ideas feministas emancipatorias originales (Conkey y Gero 1997: 414) (12). Paradójicamente, la reflexión que el feminismo anglosajón ha planteado debería afectar positivamente a otras tradiciones arqueológicas, pero se trata de un trasvase teórico unilateral, que por lo tanto debe también ser cuestionado.

(12) "French archaeologists appear perplexed by what they consider to be a historically and culturally specific AngloAmerican concern with gender, a term that, they claim, has no translation into French [Coudart, personal communication; see also del Valle $(1993 b, p$. 2) who makes a similar point for Spanish], suggesting that the genealogies of gendered anthropology are markedly Anglo-Saxon, linked to a new imperialist archaeology." (Conkey y Gero 1997: 414). 
Para finalizar, es interesante cerrar el círculo y esbozar brevemente cuáles son las aportaciones específicas potenciales que la arqueología puede hacer al feminismo. Por descontado, la arqueología puede aportar una perspectiva histórica sobre el problema del origen de la desigualdad social, y en concreto sobre el origen y la razón de la opresión de las mujeres. Metodológicamente, por otro lado, en el mundo anglosajón la arqueología contribuye sistemáticamente en las obras colectivas sobre el impacto del feminismo, en la antropología y la ciencia en general: di Leonardo 1991; Galison y Stump 1996; Brettell y Sargent 1997 y 2005; Creager et al. 2001; Schiebinger 2003... Todas ellas son obras con contribuciones de Margaret Conkey y Alison Wylie. Schiebinger (1997) empieza con una cita de J. Gero, e incluye citas de esta autora y M. Conkey. Todo esto demuestra la relevancia, en el panorama académico general internacional, de la arqueología feminista.

Pero es posible también que la arqueología tenga algo que aportar sobre la cuestión de la posición del investigador respecto a su objeto de estudio. Para el feminismo, sobre todo en términos del "punto de vista feminista", ambos, sujeto y objeto, están en el mismo plano lógico (Harding 1987: 184). Dado que el feminismo académico es una creación básicamente del ámbito de las ciencias sociales, es fácil entender esta proposición desde el punto de vista del presente espacial y temporal compartido por el sujeto y el objeto. Entre ellos el sujeto establece una distancia intelectual, por decirlo así.

Pero la arqueología es distinta; en un estudio arqueológico dicho presente no existe, y la distancia entre el sujeto y el objeto es un a priori. No puede ser establecida conscientemente por el sujeto. En todo caso, se puede establecer conscientemente la proximidad, que se construye. Eso es precisamente lo que una parte de la arqueología posprocesual ha intentado recrear perdiendo, en mi opinión, algo totalmente específico de la práctica arqueológica. Las posibilidades teóricas de este distanciamiento lógico no han sido exploradas aún por el feminismo en la práctica arqueológica. Al contrario, en algunas ocasiones, se promueve, igual que el posprocesualismo hace, una vinculación entre mujeres, sujetos y objetos, desde el presente hacia el pasado. Esa potencial falta de necesidad de esencialismo, teorizada, podría favorecer al feminismo en general.

\section{AGRADECIMIENTOS}

Mis conversaciones con Margaret Conkey y con Juan Vicent García han sido fundamentales para producir esta síntesis. Pedro Díaz del Río, Maribel Martínez Navarrete y, especialmente, Almudena Hernando Gonzalo y Margarita Sánchez Romero, me han aportado una impagable cantidad de información, tiempo y entusiasmo.

Las evaluaciones a este artículo, por otro lado, merecen un comentario especial. El tono e incluso la forma en que han sido escritas, su calidad, sus aportaciones personales y el punto de vista en el que se sitúan respecto a este texto, representan para mí una forma distinta de hacer arqueología, como lo es el feminismo. Esa clase de consistencia en todos los frentes de trabajo es nuestro modelo.

Gracias. Cualquier error es de mi responsabilidad.

Este artículo fue escrito en su primera versión durante mi estancia posdoctoral MEC/Fulbright en la University of California, Berkeley, 20062008.

\section{BIBLIOGRAFÍA}

Alberts, P. y Medicine, B. (eds.) 1983: The hidden half: studies of Plains Indian women. University Press of America. Washington DC.

Álvarez Lacambra, A. 1997: "Recordando a los conservadores de museos de la posguerra. Entrevista a María Braña de Diego". Revista de Museología 11: 48-51.

Amorós, C. y de Miguel, A. (eds.) 2005: Teoría feminista: de la ilustración a la globalización I, II y III. Minerva Ediciones, Madrid.

Arnold, K.; Gilchrist, R.; Graves, P. y Taylor, S. 1988: "Women in archaeology". Archaeological review from Cambridge 7(1): 2-8.

Balaguer Nadal, P. y Oliart Caravatti, C. 2003: "Una revalorización del trabajo femenino: análisis de la reproducción biológica desde una perspectiva socio-económica". En M.D. Molas y S. Guerra (eds.): Morir en femenino. Mujeres, ideología y prácticas funerarias desde la Prehistoria hasta la Edad Media. Universidad de Barcelona. Barcelona: XX.

Balme, J. y Beck, W. (eds.) 1995: Gendered Archaeology. The Second Australian Women in Archaeology Conference. Australian National University. Canberra. 
Baquedano Beltrán, I. 1993: “Encarnación Cabré Herreros. La primera mujer en la Arqueología española". Revista de Arqueología 146: 54-59.

Bender, B. 2000: "Introduction". En M. Donald y L. Hurcombe (eds.): Representations of gender from Prehistory to the Present. St. Martin's. Nueva York: xix-xxix.

Bender, S. 1991: "Towards a history of women in northeastern U.S. archaeology". En D. Walde y N. Willows N. (eds.): The Archaeology of Gender: Proceedings of the 22nd Annual Chacmool Conference. Archeological Association University of Calgary. Calgary: 211-216.

Bray, T. 2005: "Repatriation and archaeology's second loss of innocence: on knowledge, power and the past". Paper presented at School of American Research Conference, August 2004 "Politics, Practice and Theory: repatriation as a force of change in contemporary archaeology".

Brettel, C. y Sargent, C. (eds.) 1997: Gender in crosscultural perspective. Prentice Hall. New Jersey.

Brettel, C. y Sargent, C. (eds.) 2005: Gender in crosscultural perspective. Prentice Hall. New Jersey.

Brumfiel, E. 1991: "Weaving and cooking: women's production in Aztec Mexico". En J. Gero y M. Conkey (eds.): Engendering archaeology: women and prehistory. Blackwell. Oxford: 224-253.

Brumfiel E. 1992: "Breaking and entering the ecosystem: gender, class, and faction steal the show". American Anthropologist 94(3): 551-567.

Cárdaba Muñoz, G.; Cruz Berrocal, M.; González Murillo, C.; Mansilla Castaño, A.M.; Rodríguez de la Esperanza, M.J.; Ruiz Martín-Rubio, C. y Tormo Ortiz, M. 1998: "Las primeras generaciones de arqueólogas españolas: una aproximación". Revista d'Arqueologia de Ponent 8: 151-166.

Castro, P; Escoriza, T. y Sanahuja, E. 2003: Mujeres y hombres en espacios domésticos. Trabajo y vida social en la Prehistoria de Mallorca (c.700-500 cal ANE). El edificio Alfa del Puig Morter de Son Ferragut (Sineu, Mallorca). Archaeopress. BAR International Series 1162. Oxford.

Castro, P.; Gili, S.; Lull, V.; Micó, R.; Rihuete, C.; Risch, R. y Sanahuja, E. 1998: "Teoría de la producción de la vida social. Mecanismos de explotación en el sudeste ibérico". Boletín de antropología americana 33: 25-78.

Claassen, C. 1991: "Gender, shellfishing, and the Shell Mound Archaic". En J. Gero y M. Conkey (eds.): Engendering Archaeology: women and prehistory. Blackwell. Oxford: 276-300.

Claassen, C. (ed.) 1992: Exploring Gender through Archaeology. Prehistory Press. Madison.

Claassen, C. (ed.) 1994: Women in Archaeology. University of Pennsylvania Press. Philadelphia.
Claassen, C. y Joyce, R. (eds.) 1997: Women in Prehistory. North America and Mesoamerica. University of Pennsylvania Press. Philadelphia.

Conkey, M. (con S. Williams) 1991: Original narratives. "The political economy of gender in Archaeology". En M. di Leonardo (ed.): Gender at the crossroads of knowledge. Feminist Anthropology in the Postmodern era. University of California Press. Berkeley: 102-139.

Conkey, M. 1993: "Making the connections: Feminist theory and Archaeologies of gender". En H. du Cros y L. Smith (eds.): Women in Archaeology. A feminist critique. Australian National University. Canberra: 3-25.

Conkey, M. 1995: "Paleovisions: interpreting the imagery of Ice Age Europe". En S. Scott (ed.): The art of interpreting. Pennsylvania State University. University Park: 10-29.

Conkey, M. 1997: "Mobilizing ideologies: Palaeolithic 'art', gender trouble, and thinking about alternatives". En L. Hager (ed.): Women in human evolution. Routledge. Londres: 172-207.

Conkey, M. 2003: "Has Feminism changed Archaeology?" Signs: Journal of Women in Culture and Society 28 (3): 867-880.

Conkey, M. 2005a: "The Archaeology of gender today: new vistas, new challenges". En C. Brettel y C. Sargent (eds.): Gender in cross-cultural perspective. Prentice Hall. New Jersey: 53-62.

Conkey, M. 2005b: "Dwelling at the margins, action at the intersection? Feminist and Indigenous archaeologies, 2005". Archaeologies 1 (1): 9-80 (con comentarios).

Conkey, M. 2007: "Questioning theory: is there a gender of theory in archaeology?" Journal of Archaeological Method and Theory 14: 285-310.

Conkey, M. y Gero, J. 1991: "Tensions, pluralities, and engendering archaeology: an introduction to Women and Prehistory". En J. Gero y M. Conkey (eds.): Engendering Archaeology: Women and Prehistory. Blackwell. Oxford: 3-30.

Conkey, M. y Gero, J. 1997: "Programme to practice: Gender and Feminism in Archaeology". Annual Review of Anthropology 26: 411-437.

Conkey, M. y Spector, J. 1984: "Archaeology and the Study of Gender". En M. B. Schiffer (ed.): Advances in Archaeological Method and Theory 7. Academic Press. New York: 1-38.

Conkey, M. y Tringham, R. 1995: "Archaeology and the Goddess: exploring the contours of Feminist archaeology". En D. Stanton y A. Stewart (eds.): $\mathrm{Fe}$ minisms in the Academy. University of Michigan Press. Ann Arbor: 199-247.

Conkey, M. y Tringham, R. 1996: "Cultivating thinking/challenging authority: some experiments in feminist pedagogy in archaeology". En R. Wright 
(ed.): Gender and Archaeology. University of Pennsylvania Press. Philadelphia: 224-250.

Conkey, M. y Tringham, R. 1998: "Rethinking Figurines: A Critical View from Archaeology of Gimbutas, the 'Goddess' and Popular Culture". En L. Goodison y C. Morris (eds.): Ancient Goddesses: The Myths and the Evidence. British Museum Press. Londres: 22-45.

Colomer, L.; González Marcén, P.; Montón, S. y Picazo, M. (comp.) 1999: Arqueología y teoría feminista. Estudios sobre mujeres y cultura material en arqueología. Icaria/Antrazyt. Barcelona.

Cordell, L. 1991: "Sisters of sun and spade, women archaeologists in the Southwest". En D. Walde y N. Willows N. (eds.): The Archaeology of Gender: Proceedings of the 22nd Annual Chacmool Conference. Archeological Association University of Calgary. Calgary: 502-509.

Creager, A.; Lunbeck, E. y Schiebinger, L. (eds.) 2001: Feminism in twentieth-century. Science, technology, and medicine. The University of Chicago Press, Chicago.

Crenshaw, K. 1989: "Demarginalizing the intersection of race and sex: a black feminist critique of antidiscrimination doctrine, feminist theory and antiracist politics". University of Chicago Legal Forum: 139-167.

Chapa Brunet, T. 2005: "Espacio vivido y espacio representado: las mujeres en la sociedad ibérica". En I. Morant (dir.): Historia de las Mujeres en España y América Latina. Cátedra. Madrid: 117-137.

Davis, K. 2008: "Intersectionality as buzzword: a sociology of sicience perspective on what makes feminist theory succesful". Feminist Theory 9 (1): 67-86.

De Miguel, A. 1993: Marxismo y feminismo en Alejandra Kollontai. Instituto de Investigaciones Feministas de la UCM/CAM. Madrid.

Del Valle, T. (ed.) 1993: Gendered Anthropology. Routledge. Londres.

Díaz Andreu, M. 1998: "Spanish women in a changing world. Strategies in the search for self-fulfilment through antiquities". En M. Díaz-Andreu y M. Sørensen (coord.): Excavating Women. A History of Women in European Archaeology. Routledge. Londres: 125-145.

Díaz Andreu, M. 1998b: "Iberian post-palaeolithic art and gender: discussing human representations in Levantine Art". Journal of Iberian Archaeology 0: 33-51.

Díaz Andreu, M. 2005: “Género y arqueología: una nueva síntesis”. En M. Sánchez Romero (eds.): Arqueología y Género. Universidad de Granada. Granada: 13-51.

Díaz Andreu, M. y Sanz Gallego, N. 1994: "Women in Spanish Archaeology". En M.C. Nelson, S.M. Nelson y A. Wylie (eds.): Equity Issues for Women in
Archaeology. Archaeological Papers of the American Anthropological Association 5: 121-130.

Díaz Andreu, M. y Sørensen, M. (coord.) 1998: Excavating Women. History of Women in European Archaeology. Routledge. Londres.

Di Leonardo, M. 1991: Gender at the crossroads of knowledge. Feminist anthropology in the Postmodern era. University of California Press. Berkeley.

Dobres, M.A. y Robb, J.E. (eds.) 2000: Agency in archaeology. Routledge. Londres.

Du Cros, H. y Smith, L. (eds.) 1993: Women in Archaeology: A Feminist Critique. Australian National University. Canberra.

Ehrenberg, M. 1989: Women in Prehistory. University of Oklahoma Press. Oklahoma City.

Engelstad, E. 1991: "Images of Power and Contradiction: Feminist Theory and Post-Processual Archaeology". Antiquity 65: 502-514 (traducción española en Colomer et al. 1999).

Engelstad, E. 2007: "Much more than gender". Journal of Archaeological Method and Theory 14: 217-234.

Escoriza Mateu, T. 2002: La representación del cuerpo femenino. BAR. Oxford.

Escoriza Mateu, T. y Sanahuja Yll, E. 2005: "La prehistoria de la autoridad y la relación. Nuevas perspectivas de análisis para las sociedades del pasado". En M. Sánchez Romero (eds.): Arqueología y Género. Universidad de Granada. Granada: 109-140.

Fernández Martínez, V. 2006: Una Arqueología Crítica. Ciencia, ética y política en la construcción del pasado. Crítica, Barcelona.

Fotiadis, M. 1994: "What is Archaeology's "Mitigated Objectivism" Mitigated by? Comments on Wylie". American Antiquity 59 (3): 545-555.

Fox Keller, E. 1982: "Feminism and science". En N. Keohane, M. Rosaldo y B. Gelpi (eds.): Feminist theory. A critique of ideology. The University of Chicago Press. Chicago: 113-126.

Fox Keller, E. 1985: Reflections on gender and science. Yale University. New Haven.

Galison, P. y Stump, D. (eds.) 1996: The disunity of Science. Boundaries, contexts, and power. Stanford University Press. Palo Alto.

Gero, J. 1983: "Gender bias in Archaeology: a cross-cultural perspective". En J. Gero, D. Lacy y M. Blakey (eds.): The Sociopolitics of Archaeology. University of Massachusetts. Amherst.

Gero, J. 1985: "Socio-Politics and the Woman-at-Home Ideology". American Antiquity 50 (2): 342-350 (traducción española en Colomer et al. 1999).

Gero, J. 1993: "The social world of prehistoric facts: gender and power in Paleoindian research". En H. du Cros y L. Smith (eds.): Women in Archaeology: A Feminist Critique. Australian National University. Canberra: 31-40. 
Gero, J. y Conkey, M. (eds.) 1991: Engendering Archaeology. Women and Prehistory. Blackwell. Oxford.

Gifford-González, D. 1993: “'You can hide, but you can't run': representations of women's work in illustrations of Paleolithic life". Visual Anthropology Review 9 (1): 3-21.

Gilchrist, R. 1992: "Review of Experiencing Archaeology by Michael Shanks". Archaeological Review from Cambridge 11: 188-191.

Gilchrist, R. 1994: Gender and Material Culture: The Archaeology of Religious Women. Routledge. Nueva York.

Gilchrist, R. 1999: Gender and Archaeology: Contesting the Past. Routledge. Londres.

Gilchrist, R. 2007: "Archaeology and the life course: a time and age for gender". En L. Meskell y R. Preucel (eds.): A companion to Social Archaeology. Blackwell. Oxford: 142-160.

Gillespie, S. 2000: "Personhood, agency, and mortuary ritual: a case study from the ancient Maya". Journal of Anthropological Archaeology 20: 71-112.

González Marcén, P. 2000: “Mujeres, espacio y arqueología. Una primera aproximación desde la investigación española". En P. González Marcén (ed.): Espacios de género en arqueología. Arqueología Espacial 22. Seminario de Arqueología y Etnología Turolense. Teruel: 11-22.

González Marcén, P. 2005: "Redes de complicidades y objetos vividos". En M. Sánchez Romero (eds.): Arqueología y Género. Universidad de Granada. Granada: 491-499.

González Marcén, P. y Picazo Gurina, M. 2005: “Arqueología de la vida cotidiana”. En M. Sánchez Romero (eds.): Arqueología y Género. Universidad de Granada. Granada: 141-158.

Gregory Kohlstedt, S. y Longino, H. (eds.) 1997: Women, gender, and science. New directions. Osiris (volumen especial) 12.

Hanen, M. y Kelley, J. 1992: "Gender and archaeological knowledge". En L. Embree (ed.): Metaarchaeology: reflections by archaeologists and philosophers. Kluwer Academic Publishers. Dordrecht: 195-225.

Harding, S. 1986: The Science Question in Feminism. Cornell University Press. Ithaca.

Harding, S. (ed.) 1987: Feminism and methodology. Indiana University Press. Bloomington.

Harding, S. 1991: Whose Science? Whose Knowledge? Thinking from Women's Lives. Cornell University Press. Ithaca.

Harding, S. 1998: Is Science Multicultural? Postcolonialism, Feminism \& Epistemologies. Indiana University Press. Bloomington.

Hartsock, N. 1987: "The feminist standpoint. Developing the ground for a specifically feminist histori- cal materialism". En S. Harding (ed.): Feminism and methodology. Indiana University Press. Bloomington: $157-180$.

Hastorf, C. 1991: "Gender, space, and food in Prehistory". En J. Gero y M. Conkey (eds.): Engendering archaeology: women and prehistory. Blackwell. Oxford: 132-159.

Haug, F. 1983: “The Women's Question and the Class Question”. En S. Hänninen y L. Paldaìn (eds.): Rethinking ideology: a Marxist debate. International General. Nueva York: 144-149.

Hawkesworth, M. 1989: "Knowers, Knowing, Known: Feminist Theory and Claims of Truth". Signs: Journal of Women in Culture and Society 14 (3): 533-557.

Hernando Gonzalo, A. (ed.) 2000a: La construcción de la subjetividad femenina. Instituto de investigaciones feministas de la UCM. Madrid.

Hernando Gonzalo, A. 2000b: "Hombres del Tiempo y Mujeres del Espacio. Individualidad, poder y relaciones de género". Arqueología Espacial 22: 23-44.

Hernando Gonzalo, A. 2002: Arqueología de la identidad. Akal. Madrid.

Hernando Gonzalo, A. (ed.) 2003: ¿Desean las mujeres el poder? Cinco reflexiones en torno a un deseo conflictivo. Minerva Ediciones. Madrid.

Hernando Gonzalo, A. 2005a: "Agricultoras y campesinas en las primeras sociedades productoras". En I. Morant (dir.): Historia de las Mujeres en España y América Latina. Cátedra. Madrid: 79-116.

Hernando Gonzalo, A. 2005b: "Mujeres y Prehistoria: en torno a la cuestión del origen del patriarcado". En M. Sánchez Romero (eds.): Arqueología y Género. Universidad de Granada. Granada: 73-108.

Hernando Gonzalo, A. 2007: "Sexo, Género y Poder. Breve reflexión sobre algunos conceptos manejados en la Arqueología del Género". Complutum 18: 167-174.

Hernando, A. 2008: Género y sexo. Mujeres, identidad y modernidad. Claves de Razón Práctica 188: 64-70.

Hill Collins, P. 1989: "The Social Construction of Black Feminist Thought". Signs: Journal of Women in Culture and Society 14 (4): 745-773.

Hornos Mata, F. y Rísquez Cuenca, C. 2005: "Representación en la actualidad. Las mujeres en los museos". En M. Sánchez Romero (eds.): Arqueología y Género. Universidad de Granada. Granada: 479-490.

Jackson, T. 1991: "Pounding Acorn: Women's Production as Social and Economic Focus". En J. Gero y M. Conkey (eds.): Engendering Archaeology: women and prehistory. Blackwell. Oxford: 301-325.

Joyce, R. 2000: Gender and power in Prehispanic Mesoamerica. University of Texas Press. Austin. 
Joyce, R. 2005: "Archaeology of the body". Annual Review of Anthropology 34: 139-158.

Joyce, R. 2007: "Embodied subjectivity: gender, femininity, masculinity, sexuality". En L. Meskell y R. Preucel (eds.): A companion to Social Archaeology. Blackwell, Oxford: 82-95.

Joyce, R.; Guyer, C. y Joyce, M. 2000: Sister Stories. http://www.nyupress.org/sisterstories/index.html. New York University Press, Nueva York.

Keohane, N., Rosaldo, M. y Gelpi, B. (eds.) 1982: Feminist theory. A critique of ideology. The University of Chicago Press. Chicago.

Leacock, E. 1972: "Introduction". F. Engels, The Origin of the Family, Private Property and the State. International Publishers. Nueva York.

Leacock, E. 1978: “Women's status in egalitarian society: implications for social evolution". Current Anthropology 19 (2): 247-275.

Levine, M. 1991: "An historical overview of research on women in archaeology". En D. Walde y N. Willows N. (eds.): The Archaeology of Gender: Proceedings of the 22nd Annual Chacmool Conference. Archeological Association University of Calgary. Calgary: 177-186.

Little, B. 1994: "Consider the Hermaphroditic Mind: Comment on 'The Interplay of Evidential Constraints and Political Interests: Recent Archaeological Research on Gender'". American Antiquity 59 (3): 539-544.

Loder, N. 2000: "U.S science shocked by revelations of sexual discrimination". Nature 405 (6787): 713-714.

Longino, H. 1990: Science as social knowledge: values and objectivity in scientific inquiry. Princeton University Press. Princeton.

Mahmood, S. 2001: "Feminist theory, embodiment, and the docile agent: some reflections on the Egyptian Islamic Revival". Cultural antrhopology 6 (2): 202-236.

Mascia-Lees, F.; Sharpe, P. y Ballerino Cohen, C. 1989: "The Postmodernist turn in Anthropology: cautions from a Feminist Perspective". Signs: Journal of Women in Culture and Society 15 (1): 7-33.

Meskell, L. 1999: Archaeologies of social life: age, sex, class et-cetera in Ancient Egypt. Blackwell. Oxford.

Meskell, L. 2002: Private life in New Kingdom Egypt. Princeton University Press. Princeton.

Meskell, L. y Joyce, R. 2003: Embodied lives: figuring ancient Maya and Egyptian experience. Routledge, Londres.

Miller, V. (ed.) 1988: The role of gender in Precolumbian art and architecture. University Press of America. Lanham.

Montón Subías, S.; González Marcén, P.; Picazo, M. y Sánchez Romero, M. (eds.) 2008: Engendering so- cial dynamics: the archaeology of maintenance activities. BAR International Series 1862, Oxford.

Morant, I. (dir.) 2005: Historia de las Mujeres en España y América Latina I. Cátedra. Madrid.

Moore, H. 1988: Feminism and Anthropology. Polity Press. Cambridge (traducción española de 1999, Antropología y feminismo. Cátedra. Madrid).

Moser, S. 1998: Ancestral images: the iconography of human origins. Cornell University Press. Ithaca.

Nelson, S. 1991: "Women archaeologists in Asia and the Pacific". En D. Walde y N. Willows N. (eds.): The Archaeology of Gender: Proceedings of the 22nd Annual Chacmool Conference. Archeological Association University of Calgary. Calgary: 217-219.

Nelson, S. 1997: Gender In Archaeology: Analyzing Power and Prestige. Altamira Press. Walnut Creek.

Nelson, S. (ed.) 2006: Handbook of gender in archaeology. Altamira Press. Lanham.

Nelson, S. (ed.) 2007: Women in Antiquity: Theoretical Approaches to Gender and Archaeology. Altamira Press. Lanham.

Nelson, M.; Nelson, S. y Wylie, A. (eds.) 1994: Equity Issues for Women in Archaeology. Archaeological Papers 5. American Anthropological Association. Washington DC.

Parezo, N. (ed.) 1993: Hidden Scholars: Women Anthropologists and the Native American Southwest. University of New Mexico Press. Albuquerque.

Patai, D. y Koertge, N. 1994: Professing Feminism: Inside the Strange World of Women's Studies. New Republic/Basic Books. Nueva York.

Pattyname, P. 2006: "Intersectionality". European Journal of Women's Studies 13 (3): 187-92.

Picazo, M. 1997: "Hearth and home: the timing of maintenance activities". En J. Moore y E. Scott (ed.): Invisible people and processes. Writing Gender and Childhood into European Archaeology. Leicester University Press. Londres: 59-67.

Pollock, S. 1991: “Women in a men's world: images of Sumerian women". En J. Gero y M. Conkey (eds.): Engendering Archaeology: women and prehistory. Blackwell. Oxford: 366-387.

Preucel, R. 1995: "The postprocessual condition". Journal of Archaeological Research 3 (2): 147-175.

Querol, A. 2000: "El espacio de la mujer en el discurso sobre el origen de la humanidad". En P. González (ed.): Espacios de género en arqueología. Arqueología Espacial 22, Seminario de Arqueología y Etnología Turolense. Teruel: 161-173.

Querol, A. 2001: Adán y Darwin. Síntesis. Madrid.

Querol, A. 2005a: “"El origen del hombre' y la identidad femenina: los mitos duraderos". En M. Sánchez Romero (ed.): Arqueología y género. Universidad de Granada. Granada: 441-456. 
Querol, A. 2005b: "Las mujeres en los relatos sobre los orígenes de la humanidad". En I. Morant (dir.): Historia de las Mujeres en España y América Latina. Cátedra. Madrid: 27-77.

Querol, A. y Treviño, C. 2004: La mujer en "el origen del hombre”. Bellaterra. Barcelona.

Reyman, J. (ed.) 1992: Rediscovering Our Past: Essays on the History of American Archaeology. Avebury. Aldershot.

Roberts, C. 1993: "A critical approach to gender as a category of analysis in archaeology". En H. du Cros y L. Smith (eds.): Women in Archaeology: a feminist critique. Australian National University. Canberra: 16-21.

Romanowicz, J. y Wright, R. 1996: "Gendered perspectives in the classroom". En R. Wright (ed.): Gender and archaeology. University of Pennsylvania Press. Philadelphia: 199-224.

Sacks, K. 1974: "Engels revisited: women, the organization of production, and private property". En M. Rosaldo y L. Lamphere (eds.): Woman, Culture and Society. Stanford University Press. Palo Alto: 207-222.

Sacks, K. 1976: "State bias and women's status". American Anthropologist 78 (3): 565-569.

San Clemente Geijo, M.P. 1998: "Vera Leisner". $R e-$ vista de Arqueología 205: 56-59.

Sanahuja Y11, E. 1991: "Modelos explicativos sobre los orígenes y la evolución de la humanidad". En L. Luna (comp.): Mujeres y Sociedad. Nuevos enfoques teóricos y metodológicos. Universidad de Barcelona. Barcelona: 149-167.

Sanahuja Y11, E. 1997a: "Sexuar el pasado. Una propuesta arqueológica”. En C. Segura (coord.): La historia de las mujeres en el nuevo paradigma de la historia. A.C. Al-Mudayna. Madrid: 15-24.

Sanahuja Y11, E. 1997b: "Marxismo y feminismo". Boletín de Antropología Americana 31: 7-14.

Sanahuja Y11, E. 2001: "Feminismo, marxismo y arqueología”. Astigi Vetus 1: 55-63.

Sanahuja Y1l, E. 2002: Cuerpos sexuados, objetos y prehistoria. Cátedra. Madrid.

Sánchez Liranzo, O. 2005a: "La investigación prehistórica en Andalucía occidental. Un estudio historiográfico". En M. Sánchez Romero (eds.): Arqueología y Género. Universidad de Granada. Granada: 457-478.

Sánchez Liranzo, O. 2005b: "Hacia una arqueología más "social"'. En M. Sánchez Romero (eds.): Arqueología y Género. Universidad de Granada. Granada: 53-72.

Sánchez Romero, M. 2005 (ed.): Arqueología y Género. Universidad de Granada. Granada.

Sánchez Romero, M. 2007 (ed.): Arqueología de las mujeres y las relaciones de género. Complutum 18.

Schiebinger, L. 1997: "Creating sustainable Science". Osiris 12: 201-216.
Schiebinger, L. 2003: "Introduction". Signs: Journal of Women in Culture and Society, Issue on Feminism inside the sciences, 28 (3): 859-866.

Schmidt, R. y Voss, B. (eds.) 2000: Archaeologies of sexuality. Routledge. Londres.

Scott, J. 1986: “Gender: A Useful Category of Historical Analysis". The American Historical Review 91 (5): 1053-1075.

Scott, E. (ed.) 1994a: Those of Little Note: gender, race, and class in Historical archaeology. University of Arizona Press. Tucson.

Scott, E. 1994b: "Through the lens of gender: archaeology, inequality, and those "of little note"'. En E.M. Scott (ed.): Those of Little Note: gender, race, and class in Historical archaeology. University of Arizona Press. Tucson: 3-24.

Seifert, D.J. 1991: "Introduction". Gender in Historical Archaeology, Historical Archaeology 25 (4): $1-5$.

Shapiro, J. 1981: "Anthropology and the study of gender". En E. Langland y W. Gove (eds.): A feminist perspective in the academy. The difference it makes. The University of Chicago Press. Chicago: 110-129.

Smith, L. y Du Cros, H. 1995: Reflections on women in archaeology. En J. Balme y W. Beck (eds.): Gendered Archaeology: The Second Australian Women in Archaeology Conference. Australian National University. Canberra: 7-27.

Sørensen, M.L. Stig 2000: Gender Archaeology. Polity Press. Cambridge.

Spector, J. 1991: "What this awl means: toward a feminist archaeology". En J. Gero y M. Conkey (eds.): Engendering archaeology: women and prehistory. Blackwell. Oxford: 388-406 (traducción española en Colomer et al. 1999).

Spector, J. 1993: What This Awl Means: Feminist Archaeology in a Wahpeton Dakota Village. Minnesota Historical Society. Minneapolis.

Spector, J. y Whelan, M. 1989: "Incorporating gender into Archaeology courses". En S. Morgen (ed.): Gender and Anthropology: critical reviews for research and teaching. American Anthropological Association. Washington DC: 65-94.

Spender, D. 1985: Man Made Language. Routledge \& Kegan Paul. Londres [original de 1980].

Spriggs, M. 1993: “Quantifying women's oppression in prehistory: the Aneityum (Vanuatu) case". En H. du Cros y L. Smith (eds.): Women in Archaeology: A Feminist Critique. Australian National University. Canberra: 143-150.

Strathern, M. 1983: “Applied Feminism”. RAIN 54: $1-2$.

Tomášková, S. 2007: "Mapping a Future: Archaeology, Feminism, and Scientific Practice". Journal of Archaeological Method and Theory 14: 264-284.

T. P., 66, N. ${ }^{\circ} 2$, julio-diciembre 2009, pp. 25-43, ISSN: 0082-5638

doi: $10.3989 /$ tp.2009.09026 
Tringham, R. 1991: "Households with faces: the challenge of gender in prehistoric architectural remains". En J. Gero y M. Conkey (eds.): Engendering archaeology: women and prehistory. Blackwell. Oxford: 93-131 (traducción española en Colomer et al. 1999).

Vargas, I. 2004: "Hacia una teoría feminista en arqueología". Otras miradas 4 (2): 62-75.

Voss, B. 2000: "Feminisms, Queer Theories, and the Archaeological Study of Past Sexualities". World Archaeology (Queer Archaeologies) 32(2): 180-192.

Walde, D. y Willows, N. (eds.) 1991: The Archaeology of Gender: Proceedings of the 22nd Annual Chacmool Conference. Archeological Association University of Calgary. Calgary.

Wall, D. 1994: The Archaeology of Gender: Separating the spheres in Urban America. Plenum. Nueva York.

Watson, P. y Kennedy, M. 1991: "The Development of Horticulture in the Eastern Woodlands of North America: Women's Role". En J. Gero y M. Conkey (eds.): Engendering archaeology: women and prehistory. Blackwell. Oxford: 255-275.

Wiber, M. 1997: Erect men, undulating women: the visual imagery of gender, race and progress in reconstructive illustrations of human evolution. Wilfrid Laurier University Press. Waterloo.

Wilkie, L. y Howlett Hayes, K. 2006: "Engendered and feminist archaeologies of the recent and documented pasts". Journal of Archaeological Research 14: 243-264.
Wolff, J. 1990: Feminine sentences. University of California Press. Berkeley.

Wright, R. (ed.) 1996: Gender and Archaeology. University of Pennsylvania Press. Philadelphia.

Wylie, A. 1992: "The Interplay of Evidential Constraints and Political Interests: Recent Archaeological Research on Gender". American Antiquity 57 (1): 15-35 (traducción española en Colomer et al. 1999).

Wylie, A. 1994: 'On 'Capturing facts alive in the past' (or present): response to Fotiadis and to Little". American Antiquity 59 (3): 556-560.

Wylie, A. 1996: "The constitution of archaeological evidence: gender politics and science”. En P. Galison y D. Stump (eds.): The Disunity of Science. Boundaries, Contexts, and Power. Stanford University Press. Palo Alto: 311-343.

Wylie, A. 1997: "The engendering of archaeology: refiguring feminist science studies". Osiris 12: 80-99.

Wylie, A. 2000: "Questions of evidence, legitimacy, and the (Dis)Unity of Science". American Antiquity 65 (2): 227-237.

Wylie, A. 2001: "Doing Social Science as a Feminist: the engendering of Archeology". En A. Creager, E. Lunbeck y L. Schiebinger (eds.): Feminism in twentieth-century. Science, technology and medicine. The University of Chicago Press. Chicago: 23-45.

Wylie, A. 2002: Thinking from things. Essays in the Philosophy of Archaeology. University of California Press. Berkeley. 